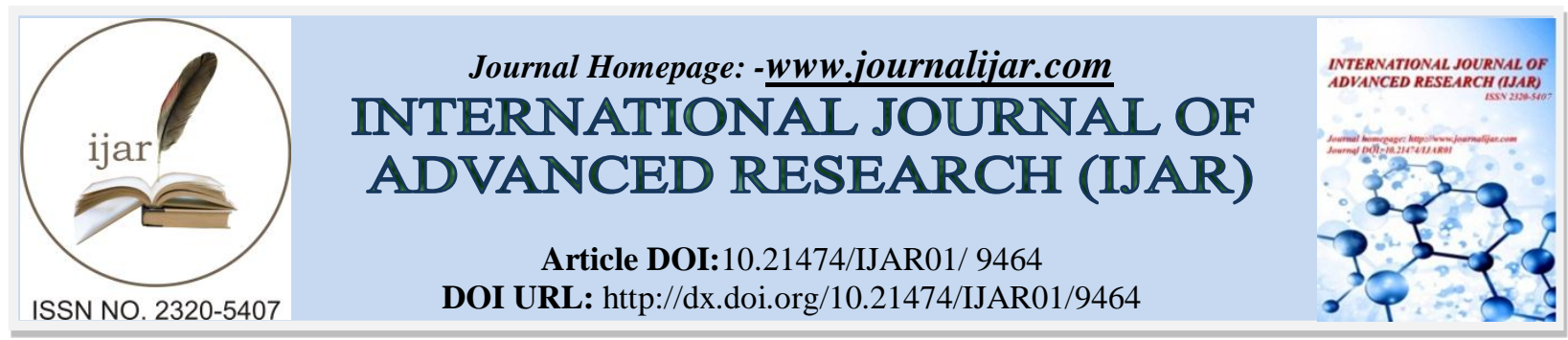

RESEARCH ARTICLE

\title{
HISTOPATHOLOGICAL SPECTRUM OF NON-NEOPLASTIC LESIONS IN UTERINE CERVIX - A ONE YEAR RETROSPECTIVE STUDY.
}

\author{
Bhavneet Kour ${ }^{1}$ And Ameet Kaur². \\ 1. Senior resident, Department of pathology, Govt. Medical College Jammu(J\&K), India. \\ 2. Assistant professor,Department of pathology, Govt. Medical College Jammu(J\&K), India.
}

\section{Manuscript Info}

Manuscript History

Received: 27 May 2019

Final Accepted: 29 June 2019

Published: July 2019

Key words:-

Cervix, Histopathology, Hyperplasia,

Non-neoplastic lesions, Metaplasia.

\section{Abstract}

Background: The uterine cervix is a gateway to many neoplastic and non-neoplastic lesions. Non-neoplastic lesions of cervix constitute a wide variety of lesions in the hysterectomy or cervical biopsy specimen. Most of these lesions are commonly seen in women of reproductive age group. The aim of the current study was to analyze the prevalence and histological types of various non-neoplastic lesions of the cervix.

Materials and methods: The present retrospective study includes 200 non-neoplastic cervical lesions which were analyzed from either hysterectomy or cervical biopsy specimens received in the Department of Pathology, Government Medical College Jammu over a period of one year. All the slides of cervix were retrieved from histopathology slide records and were reviewed. Whenever required the blocks were retrieved and recut of the sections were done.

Results: The study includes 300 cases of non-neoplastic cervical lesions received as a part of hysterectomy or cervical biopsy and categorized into a variety of lesions. The most common lesion was inflammatory, reactive or reactive $224(74.6 \%)$ cases followed by glandular hyperplasia in $44(14.6 \%)$ cases, metaplasia in $22(7.4 \%)$ cases and benign neoplasm in $10(3.4 \%)$ cases.

Conclusion: The spectrum of cervical lesions is vast and therefore early detection, categorization and management of certain lesions can help in preventing the complications and reducing the morbidity.

Copy Right, IJAR, 2019,. All rights reserved.

\section{Introduction:-}

Cervix is a gateway to many neoplastic and non-neoplastic lesions [1]. Cervix cancer is the second most common cancer worldwide having poor prognosis. Non-neoplastic lesions of the cervix constitute a large proportion of diagnosis, obtained from small biopsy or hysterectomy specimens. They are seen across all women with peak in reproductive age group. Histopathologic study of the cervix is very important for early diagnosis of the cervical diseases as they have advantage of being readily available, relatively cheap and technically easy [2].

Majority of non-neoplastic lesions are inflammatory in nature [3]. Inflammatory lesions of clinicopathological importance are acute cervicitis, chronic cervicitis and chronic granulomatous cervicitis [3,4]. These can result from 
both infective and non-infective etiology. Infective causes of acute and chronic cervicitis include a wide spectrum ranging from bacterial, viral, protozoan and fungi microorganisms commonly encountered in sexually transmitted infections (STIs) and urinary tract infections (UTIs) [5].

Carcinoma cervix is the commonest malignancy in Indian women. Early sexual activity, sexually transmitted diseases, viral infections, low socioeconomic status, injury related to multiple births are the various factors contributing for the carcinoma cervix [5].

Although, there is accessibility of the cervix to direct examination, clinical diagnosis still remains obscure. The diagnostic procedures like cervical cytology have an advantage to screen for cervical diseases. However, there is poor correlation in cervical cytology findings with their subsequent cervical biopsy reports. Therefore, histomorphological examination of the cervical lesions still remains gold standard for the diagnosis of nonneoplastic lesions of uterine cervix [6].

Tumor-like non-neoplastic cervical lesions according to the World Health Organization include endocervical hyperplasia, endometriosis, nabothian cyst, endocervical polyps [7].

Incidence of non-neoplastic and neoplastic cervical lesions vary according to the different age groups. Early recognition of infections and inflammatory lesions can prevent considerable damage to the cervix. It also helps to decrease morbidity and mortality.

The aim of the current study is to analyze the prevalence and histological types of various non-neoplastic lesions of the cervix.

\section{Materials And Methods:-}

The present retrospective study includes 200 non-neoplastic cervical lesions which were analyzed from either hysterectomy or cervical biopsy specimens received in the Department of Pathology, GMC Jammu over a period of one year from February 2018 to January 2019.

All the slides of cervix were retrieved from histopathology slide records and were reviewed. Whenever required the blocks were retrieved and recut of the sections were done. All the benign lesions of the uterine cervix involving ectocervix and endocervix were included. Inadequate biopsy specimens without lining epithelium and inadequate stromal fragment and specimen diagnosed as malignant was excluded from the study. The non-neoplastic lesions of the uterine cervix were divided into 4 categories (Table.1) based on the etiology and histomorphological examination [8].

Category 1: Inflammatory, reactive and reparative lesions

Category 2: Glandular hyperplasias

Category 3: Metaplasias and ectopies

Category 4: Benign neoplasms

Table 1:-Diagnostic category and various disease conditions

\begin{tabular}{|l|l|l|}
\hline S.N & DIAGNOSTIC CATEGORY & DIAGNOSIS \\
\hline 1. & Inflammatory, reactive and reparative lesions & $\begin{array}{l}\text { Chronic cervicitis } \\
\text { Papillary endocervicitis } \\
\text { Koilocytic change } \\
\text { Follicular cervicitis }\end{array}$ \\
\hline 2. & Glandular hyperplasia & $\begin{array}{l}\text { Nabothian cyst } \\
\text { Endocervical hyperplasia } \\
\text { Tunnel clusters }\end{array}$ \\
\hline 3. & Metaplasia and ectopias & $\begin{array}{l}\text { Squamous metaplasia } \\
\text { Prolapse changes with metaplasia }\end{array}$ \\
\hline 4. & Benign neoplasm & $\begin{array}{l}\text { Endocervical polyp } \\
\text { Leiomyomatous polyp } \\
\text { Endometriosis }\end{array}$ \\
\hline
\end{tabular}




\section{Results:-}

The study includes 300 cases of non-neoplastic cervical lesions received as a part of hysterectomy or cervical biopsy and categorized into a variety of lesions.

Table 2:-shows various diagnostic categories and its prevalence

\begin{tabular}{|l|l|l|l|}
\hline S.No & DIAGNOSTIC CATEGORY & FREQUENCY & PERCENTAGE \\
\hline 1. & Inflammatory, reactive and reparative lesions & 224 & 74.6 \\
\hline 2. & Glandular hyperplasia & 44 & 14.6 \\
\hline 3. & Metaplasia and ectopias & 22 & 7.4 \\
\hline 4 & Benign neoplasm & 10 & 3.4 \\
\hline & Total & 300 & 100 \\
\hline
\end{tabular}

Inflammatory lesions were seen in $224(74.6 \%)$ cases followed by glandular hyperplasia in 44 (14.6\%) cases, metaplasia in 22 cases and benign neoplasm in 10 cases.

Table 3:-shows histological types of non-neoplastic cervical lesions

\begin{tabular}{|l|l|l|l|}
\hline S.No & HISTOLOGICAL DIAGNOSIS & FREQUENCY & PERCENTAGE \\
\hline 1. & Chronic non-specific cervicitis & 212 & 70.7 \\
\hline 2. & Nabothian cyst & 30 & 10.0 \\
\hline 3. & Squamous metaplasia & 14 & 4.7 \\
\hline 4. & Papillary endocervicitis & 12 & 4.0 \\
\hline 5. & Endocervical hyperplasia & 10 & 3.3 \\
\hline 6. & Prolapse changes with metaplasia & 8 & 2.7 \\
\hline 7. & Endocervical polyp & 7 & 2.3 \\
\hline 8. & Tunnel clusters & 4 & 1.3 \\
\hline 9. & Leiomyomatous polyp & 2 & 0.7 \\
\hline 10. & Endometriosis & 1 & 0.3 \\
\hline & Total & 300 & 100 \\
\hline
\end{tabular}

The commonest endocervical lesions were chronic non-specific cervicitis (70.7\%) followed by Nabothian cyst (10.0\%), squamous metaplasia (4.7\%), endocervicitis (4.0\%), endocervical hyperplasia (3.3\%) and few cases of tunnel clusters $(1.3 \%)$ and leiomyomatous polyp $(0.7 \%)$. Only one case of endometriosis was found.

Table 4:-shows age wise distribution of non-neoplastic cervical lesions

\begin{tabular}{|l|l|l|}
\hline AGE RANGE & FREQUENCY & PERCENTAGE \\
\hline$<30$ years & 21 & 7.0 \\
\hline $31-40$ years & 62 & 20.7 \\
\hline $41-50$ years & 128 & 42.6 \\
\hline $51-60$ years & 65 & 21.7 \\
\hline$>60$ years & 24 & 8.0 \\
\hline
\end{tabular}

The mean age of the patient was 45.5 years, the youngest being 29 years old and the oldest 80 years old. Most of the non-neoplastic lesions were encountered in the $4^{\text {th }}$ to $6^{\text {th }}$ decade of life.

\section{Discussion:-}

A vast number of benign lesions in the cervix are encountered in day to day practice. Many of these are rare, not given much importance but can mimic in situ and invasive neoplastic lesions [8].

Olutoyin $\mathrm{G}$ et.al [9] reported that $82 \%$ of nonneoplastic lesions of the cervix occur predominantly in sexually active age group and most commonly inflammatory in nature. They may be acute or chronic; each of these can be either infective or non-infective cause. Sexually transmitted diseases, chronic Granulomatous inflammation and viruses especially Human papilloma virus and Herpes simplex virus persistently infect the cervix. Chemical irritants, douching, local trauma and foreign bodies like intrauterine contraceptive devices, pessaries and tampons can cause secondary infections. 
Inflammatory reactive and reparative lesions were the most common lesion encountered in our study. Chronic nonspecific cervicitis $212(70.7 \%)$ cases were the most common finding. It is similar to the study done by OmoniyiEsan et al. where chronic nonspecific cervicitis accounted for $82 \%$ of all non-neoplastic lesions [3]. It was seen associated with other lesions like squamous metaplasia, nabothian cyst, tunnel clusters and endocervical hyperplasia. Paaronen $\mathbf{J}$ et al [10] has stated that the etiology of chronic non-specific cervicitis is variable and is of importance because it may lead to endometritis, salpingitis and "pelvic inflammatory disease" through ascending intraluminal spread, and it may also play a role in the initiation or promotion of neoplasm.

In our study chronic nonspecific cervicitis occurred between the age range of 20-79 years with a peak incidence at the $5^{\text {th }}$ decades of life. No case was seen before menarche. This is comparable to previous reports by Craig and Lowe [11]. Other lesion encountered in the category were papillary endocervicitis 12 cases (4.0\%). Papillary cervicitis comprises papillae of various sizes which are filled with inflammatory cells. This is not really a mimic unless florid when the main differential diagnosis to consider is a villoglandular adenocarcinoma [8].

No case of TB cervicitis was found in the study. The reason being that TB is an extremely rare finding accounting for $0.1 \%$ to $0.6 \%$ of cases world wide and it usually affect the upper genital tracts mainly the endometrium and fallopian tubes [12].

The second group, glandular hyperplasia was seen in 44(14.6\%) of the cases. Endocervical hyperplasia was a less common finding seen in $3.3 \%$ of non -neoplastic cervical lesions with prevalence in the $5^{\text {th }}$ decade of life and is usually an incidental finding. Our findings were similar to the study by Pallipady et al where this lesion was seen in $4.3 \%$ of non-neoplastic cervical biopsies [4].

Nabothian cyst was seen in 30(10.0\%) cases. Our results found in the study were slightly lower than the study conducted by Krishna Dubey et al [13] where it was seen in 49(19.7\%) cases. Nabothian cyst is thought to arise due to blockage of endocervical glands and associated changes. They appear grossly cystic spaces filled with mucin and microscopically lined by flattened epithelium which when extend deep into the endocervical wall may be mistaken for malignancy [14].

Tunnel clusters was found in 4(1.3\%) cases. All the tunnel clusters were incidental findings in cervices which were removed for unrelated causes, and was in correlation as observed by Aravind pallipady et al [4] 2.7\%, and Fluhmann et al. [15]. Tunnel clusters are two types of type A which is noncystic, comprises of small closely packed glands often in a lobular architecture and Type B are cystic and usually near the surface and not deep in the stroma. However, when they do have glands reaching deep into the stroma, they can mimic the microcystic variant of usual endocervical adenocarcinoma [8].

The third group metaplasia and ectopias were observed in 22(7.4\%) cases with mean age group being 41-50 years. Squamous metaplasia was seen in 14(4.7\%) cases and was the commonest finding. Study conducted by Aravind Pallipady et al [4] showed squamous metaplasia, in (73.20\%) which was much higher than our study. Squamous metaplasia is the most common metaplasia of the cervix occurring at the transformation zone.

Among the fourth category endocervical polyp was seen in the study in 7(2.3\%) cases. A study conducted by Barut et al [16] revealed that endocervical polyps occurred in 2 to 5 percent. These occur mainly in the 4th to 6th decades of life which correlated with our findings. Endocervical polyp can be vascular, fibrous or heavily inflamed and there were often microglandular hyperplasia. Within these polyps, there can be CIN or CGIN [8]. Endocervical polyps are not true polyps but are thought to be associated with chronic inflammatory changes (polypoid cervicitis). Polyps with branching papillary configurations are termed papillary endocervicitis [16].

Endometriosis, Endocervical hyperplasia, and endocervical polyp are nonneoplastic tumor-like conditions sometimes misinterpreted as neoplastic lesion thus leading to inappropriate and aggressive treatment [17]. We reported only a single case of cervical endometriosis.

\section{Conclusion:-}

A large number of non-neoplastic lesions of cervix are commonly encountered in cervical biopsies and hysterectomy specimens. Women of reproductive age group are more prone these conditions. The spectrum of cervical lesions is 
vast and therefore early detection, categorization and management of certain lesions can help in preventing the complications and reducing the morbidity.

\section{References:-}

1. Nwachokor FN, Forae GC. Morphological spectrum of non-neoplastic lesions of the uterine cervix in Warri, South-South, Nigeria. Niger J Clin Pract 2013;16:429-32.

2. International Agency for Research on Cancer. IARC Handbooks of Cancer Prevention, Vol. 10. Lyon, France: IARC, 2005. [Cited 2018 March 03].

3. Omoniyi-Esan OG, Osasan SA, Ojo OS. Non-neoplastic diseases of the cervix in Nigeria: A histopathological study. Afr Health Sci 2006;6:76-80.

4. Pallipady A, Illanthody S, Vaidya R, Ahmed Z, Suvarna R, Metkar G. A Clinico-Morphological Spectrum of the Non-Neoplastic Lesions of the Uterine Cervix at AJ Hospital, Mangalore. J Clin Diagn Res 2011;5: 546-50

5. Chakraborty P, Roy A, Bhattacharya S, Addhya S, Mukherjie S. Tuberculous cervicitis: A clinicopathological and bacteriological study. J Indian Med Assoc 1995;93:167-8.

6. Mostafa MG, Srivannuboon s, Rachanawutanon M. Accuracy of cytological findings in abnormal cervical smears by cytohistologic comparison. Indian J Pathol Microbiol 2000;43(10):23-29.

7. Siimionescu C, Margaritescu CL, Georgescu CV, Mogoanta L, Marinescu AM. Pseudo-tumoral lesions of the cervix. Rom J MorpholEmbryol 2005;46:239-47.

8. Manek S. Benign mimics of cervical cancers. J Diagn Pathol 2015;10:1-13.

9. Olutoyin G, Omoniyi-Esan OG, Osasan SA, Ojo OS. Nonneoplastic diseases of the cervix in Nigeria. A histopathological study. Afr Health Sci 2006;6:76-80.

10. Paavonen J, Critchlow CW, DeRouen T, Stevens CE, Kiviat N, Brunham RC et al. Etiology of cervical inflammation. Am J Obstet Gynecol 1986;54:556- 64.

11. Craig P, Lowe D. Non-neoplastic lesions of the cervix. In: Fox H, Well M, (eds). Haines and Taylor Obstetrical and Gyanecological pathology. 5th ed. Churchill Livingstone: Edinburgh; 2003. pp 273-96.

12. Richards MJ, Angus D. Possible sexual transmission of genitourinary tuberculosis. Int J Tuberc Lung Dis 1998;2:439.

13. Dubey K, Garewal J, Kumar N, Sharma R. Histopathological study of Non Neoplastic lesion in cervix at tertiary center. Int J Med Res Health Sci. 2016;5:42-9

14. Philip B. Clement, Robert H. Young. Deep Nabothian Cysts of the Uterine Cervix. A Possible Source of Confusion with Minimal-Deviation Adenocarcinoma (Adenoma Malignum). Int J Gynecol Pathol 1989; 8:3408.

15. Fluhmann CF. Focal hyperplasia (tunnel clusters) of the cervix uteri. Obstel Gynecol 1961;17:206-14.

16. Barut MU, Kale A, Kuyumcuoğlu U, Bozkurt M, Ağaçayak E, Özekinci S, Gul T. Analysis of sensitivity, specificity, and positive and negative predictive values of smear and colposcopy in diagnosis of premalignant and malignant cervical lesions. Medical science monitor: international medical journal of experimental and clinical research. 2015;21:3860.

17. Kumar BJ, Annam V. Clinico-Pathological Study of Non-Neoplastic Lesions of Uterine Cervix with their Histopathological Categorization. International Journal of Science and Research. 2013: 2319-7064. 